\title{
Rapid measurement of RH-dependent aerosol hygroscopic growth using a humidity-controlled fast integrated mobility spectrometer (HFIMS)
}

\author{
Jiaoshi Zhang ${ }^{1}$, Steven Spielman ${ }^{2}$, Yang Wang ${ }^{1,3}$, Guangjie Zheng ${ }^{1}$, Xianda Gong ${ }^{1}$, Susanne Hering ${ }^{2}$, and Jian Wang ${ }^{1}$ \\ ${ }^{1}$ Center for Aerosol Science and Engineering, Washington University in St. Louis, St. Louis, Missouri, USA \\ ${ }^{2}$ Aerosol Dynamics Inc, Berkeley, California, USA \\ ${ }^{3}$ Department of Civil, Architectural and Environmental Engineering, Missouri University of Science and Technology, \\ Rolla, Missouri, USA
}

Correspondence: Jian Wang (jian@wustl.edu)

Received: 27 March 2021 - Discussion started: 29 April 2021

Revised: 8 July 2021 - Accepted: 10 July 2021 - Published: 18 August 2021

\begin{abstract}
The ability of aerosol particles to uptake water (hygroscopic growth) is an important determinant of aerosol optical properties and radiative effects. Aerosol hygroscopic growth is traditionally measured by humidified tandem differential mobility analyzers (HTDMA), in which size-selected dry particles are exposed to elevated relative humidity (RH), and the size distribution of humidified particles is subsequently measured using a scanning mobility particle sizer. As a scanning mobility particle sizer can measure only one particle size at a time, HTDMA measurements are time consuming, and ambient measurements are often limited to a single RH level. Pinterich et al. (2017b) showed that fast measurements of aerosol hygroscopic growth are possible using a humidity-controlled fast integrated mobility spectrometer (HFIMS). In HFIMS, the size distribution of humidified particles is rapidly captured by a water-based fast integrated mobility spectrometer (WFIMS), leading to a factor of $\sim 10$ increase in measurement time resolution. In this study we present a prototype HFIMS that extends fast hygroscopic growth measurements to a wide range of atmospherically relevant RH values, allowing for more comprehensive characterizations of aerosol hygroscopic growth. A dual-channel humidifier consisting of two humidity conditioners in parallel is employed such that aerosol RH can be quickly stepped among different RH levels by sampling from alternating conditioners. The measurement sequence is also optimized to minimize the transition time between different particle sizes. The HFIMS is capable of measuring
\end{abstract}

aerosol hygroscopic growth of six particle diameters under five RH levels ranging from $20 \%$ to $85 \%$ (30 separate measurements) every $25 \mathrm{~min}$. The performance of this HFIMS is characterized and validated using laboratory-generated ammonium sulfate aerosol standards. Measurements of ambient aerosols are shown to demonstrate the capability of HFIMS to capture the rapid evolution of aerosol hygroscopic growth and its dependence on both size and RH.

\section{Introduction}

Hygroscopic growth is a key determinant of the liquid water content, optical properties, and radiative effects of atmospheric aerosols (Tang and Munkelwitz, 1994; Pilinis et al., 1995; Swietlicki et al., 2008). Water uptake by particles increases light scattering, promotes heterogeneous chemical reactions, and is essential for the formation of cloud droplets (Wang et al., 2002; Wex et al., 2009; Surratt et al., 2010; George and Abbatt, 2010). Aerosol hygroscopic growth is mostly measured using a humidified tandem differential mobility analyzer (HTDMA) (Rader and McMurry, 1986; Swietlicki et al., 2008; Duplissy et al., 2009; Massling et al., 2011; Lopez-Yglesias et al., 2014). In an HTDMA, dry and charged particles are first size-selected by a differential mobility analyzer (DMA), then exposed to elevated relative humidity (RH) in a humidity conditioner. The size distribution of humidified particles, which provides the distribution of 
particle hygroscopic growth factor, is measured by a second DMA using the scanning mobility technique. Whereas in theory HTDMA can measure aerosol hygroscopic growth at a variety of humidity values, field measurements are mostly limited to a single RH level in practice because of (1) the time-consuming scanning mobility measurements and (2) the long transition time required for aerosol sample flow RH to stabilize after setpoint change (Santarpia et al., 2005). Typically, a measurement cycle for five different particle sizes at a single $\mathrm{RH}$ requires a minimum of $30 \mathrm{~min}$ (e.g., Cerully et al., 2011).

Particle hygroscopic growth is a function of $\mathrm{RH}$ and the hygroscopicity parameter (Petters and Kreidenweis, 2007), which is a function of particle composition and often varies strongly with particle size (e.g., Peng et al., 2020). Both RH and aerosol composition can exhibit strong temporal and spatial variabilities (Tang et al., 2019). In addition, the hygroscopicity parameter can vary substantially with RH (Pajunoja et al., 2015; Rastak et al., 2017; Liu et al., 2018; Peng et al., 2020). Therefore, measurements under a wide range of $\mathrm{RH}$ are often needed to comprehensively characterize aerosol hygroscopic growth behavior in the atmosphere (Sorooshian et al., 2008; Hersey et al., 2009; Rastak et al., 2017). RHdependent hygroscopic growth measurements can also help capture the phase transition of aerosols with different chemical compositions, i.e., inorganic salts exhibit deliquescent behavior while organics often do not (Tang and Munkelwitz, 1994).

Several instruments have been developed to improve the measurement speed such that hygroscopic growth can be characterized at multiple RHs with sufficient time resolution (e.g., Stolzenburg et al., 1998; Leinert and Wiedensohler, 2008; Sorooshian et al., 2008). Recently, Pinterich et al. (2017b) showed that aerosol hygroscopic growth measurements can be significantly accelerated using a humiditycontrolled fast integrated mobility spectrometer (HFIMS). In essence, HFIMS replaces the second DMA in traditional HTDMA with a water-based fast integrated mobility spectrometer (WFIMS), which captures the size distribution of humidified particles instantly (Pinterich et al., 2017b; Wang et al., 2019). In this study, we present a prototype HFIMS that extends the fast hygroscopic growth measurements to a wide range of $\mathrm{RH}$ conditions ( $20 \%$ to $85 \%$ ). A newly designed dual-channel humidifier is employed to allow quick changes of the aerosol sample flow RH. In addition, the measuring sequence is optimized to reduce the "dead time" during the transitions between different sizes of classified particles. The performance of the HFIMS is characterized using laboratory-generated ammonium sulfate aerosol standards. Ambient aerosols in a St. Louis urban area were measured using the HFIMS, and the results are presented to demonstrate the capability of the HFIMS for capturing the evolution of the hygroscopic growth factor distribution and its dependence on particle size and RH.

\section{Methods}

\subsection{Dual-channel HFIMS}

One challenge for fast hygroscopic growth measurements at multiple RH levels is the lengthy time required for conventional humidity conditioners to stabilize following a change of the RH setpoint. The humidity conditioning of size-classified particles is mostly achieved using a Nafion exchanger. Due to the relatively slow diffusion of water molecules through the Nafion membrane, it often takes a few minutes or more for the Nafion exchanger to reach a new $\mathrm{RH}$ setpoint. Lopez-Yglesias et al. (2014) used a "membraneless" diffusion-based humidifier to accelerate the transition between sample RH setpoints. In their HTDMA, it takes about $4 \mathrm{~min}$ for the system to stabilize for a 5\%-20\% (absolute value) change in the RH setpoint. The HFIMS developed here employs a dual-channel humidifier that allows for a quick change of the sample aerosol RH (Fig. 1). In the HFIMS, the sample aerosol is first dried to below $20 \%$ RH by a Nafion dryer (MD-110 series, Perma Pure LLC), brought to a steady-state charge distribution in a soft Xray aerosol neutralizer (Model 3087, TSI Inc), then sizeclassified by a DMA (Model 3081, TSI Inc.). The classified aerosol sample is subsequently introduced into a dualchannel humidifier that consists of two identical Nafion exchangers (MD-110 series, Perma Pure LLC) that condition the size-selected aerosol at two RH setpoints independently. The shell flows of the Nafion exchangers are generated by mixing humid air from a bubble humidifier and dry air. The bubble humidifier is slightly heated to compensate for evaporative cooling. The RH of the aerosol sample flow is controlled by a proportional-integral-derivative (PID) controller that varies the flow rate ratio of humid air to dry air through a proportional solenoid valve (FSV12, Omega Engineering Inc) on the dry air line. The size distribution of humidified aerosols is rapidly captured by a WFIMS operated with a constant separator voltage (Pinterich et al., 2017a). The average transport time of aerosols in the humidification section, including the Nafion exchanger and the tubing leading to the WFIMS separator inlet, is $\sim 3.2 \mathrm{~s}$. The WFIMS combines the fast integrated mobility spectrometer (FIMS) developed by Kulkarni and Wang (2006a, b) and the laminar flow water-based condensation methodology of Hering et al. (2014). As with a conventional scanning mobility particle sizer (SMPS), WFIMS uses a drift tube to separate particles of differing electrical mobility sizes. But instead of counting particles of one mobility size at a time, WFIMS counts all sizes of mobility separated particles at once. Its parallel plate mobility separator is followed by a condensational growth and imaging system. At the end of the separator, particles are distributed across the sheath flow according to their mobilities. The entire flow continues into a condensational growth section that enlarges the particles while they continue along their laminar flow trajectories. At the end of 
the growth section a sheet of laser light illuminates the grown droplets, and this two-dimensional image is captured using a digital camera (Fig. 1). The imaging system detects individual droplets and records their particle mobility-dependent position, from which the complete size distribution is derived. The dynamic range of WFIMS is roughly a factor of 10 in mobility, which translates into at least a factor of 3 in the particle diameter range. Therefore, the size range of WFIMS at a single voltage is sufficient to cover the growth factors from 0.8 to 2.4. Here, the WFIMS sheath flow is generated by mixing particle-free dry air with filtered humid air from another slightly heated bubble humidifier. The sheath flow $\mathrm{RH}$ is maintained at the same setpoint as that of the aerosol sample flow by adjusting the ratio of humid and dry air flow rates, which are controlled individually by a mass flow controller (Fig. 1). The total flow rate of the humid and dry air flows is $18.0 \mathrm{~L} \mathrm{~min}^{-1}$, slightly above the WFIMS sheath flow rate of $14.9 \mathrm{~L} \mathrm{~min}^{-1}$, and the excess is exhausted. The total flow rate of WFIMS, i.e., the sum of sample and sheath flow rates, is controlled at $15.2 \mathrm{~L} \mathrm{~min}^{-1}$ by a critical orifice. The sample flow rate is monitored using a laminar flow element (LFE) and maintained at $0.3 \mathrm{~L} \mathrm{~min}^{-1}$ through adjusting the sheath flow rate using a proportional solenoid valve (0248A, MKS Instruments) driven by a PID controller (Pinterich et al., 2017a).

The sample flow RH is monitored by a probe (HMP 60, Vaisala Inc.) immediately downstream of each Nafion exchanger. A higher sample flow rate of $0.6 \mathrm{~L} \mathrm{~min}^{-1}$ is employed for both Nafion exchangers to reduce particle diffusion loss and the response time of the $\mathrm{RH}$ probe to the $\mathrm{RH}$ change inside the exchanger. Given the WFIMS sample flow rate of $0.3 \mathrm{~L} \mathrm{~min}^{-1}$, the extra $0.3 \mathrm{~L} \mathrm{~min}^{-1}$ is exhausted just upstream of the WFIMS sample flow inlet. Due to the very large sheath to sample flow ratio (i.e., 14.9/0.3), RH inside the WFIMS is dominated by sheath flow RH, which is measured using a probe with high accuracy (HMP 110, Vaisala Inc.). A chilled mirror hygrometer (OptiSonde, General Eastern Instruments) is also operated inline to measure the dew point of WFIMS sheath flow for periodic calibration of the sheath flow RH probe. The aerosol flow rate of the upstream DMA is dictated by the total flow rate of the dual-channel humidifier of $1.2 \mathrm{~L} \mathrm{~min}^{-1}$. The DMA sheath flow rate is maintained at $12 \mathrm{~L} \mathrm{~min}^{-1}$ through a closed loop to achieve a $10: 1$ sheath to aerosol flow ratio.

\subsection{RH control and stepping}

As WFIMS quickly captures the size distribution of humidified particles, the major obstacle for fast hygroscopic growth measurements at multiple $\mathrm{RH}$ levels is the long transition time (e.g., $\sim 5 \mathrm{~min}$ ) for the Nafion exchanger to stabilize following changes of the RH setpoint. In the new HFIMS, the transition time is minimized by using the dual-channel humidifier. The sample flow RHs of the two parallel Nafion exchangers are controlled independently. When the WFIMS samples aerosol conditioned by one Nafion exchanger, the other exchanger equilibrates to the next RH setpoint. The transition time between measurements at different RH levels is therefore minimized by sampling aerosols conditioned by the two exchangers alternately. With the dual-channel humidifier design, the transition time is now dictated by the stabilization of the WFIMS sheath flow RH, which is maintained at the same setpoint as that of the aerosol sample. The sheath flow RH is controlled by adjusting the mixing ratio of the humid and dry air flows, which are controlled by mass flow controllers (Alicat Scientific) that have much faster responses. This approach leads to a faster control and stabilization of RH than in the Nafion exchanger. It requires less than $60 \mathrm{~s}$ for the sheath flow RH to be within $0.5 \%$ of the setpoint for a step change of $20 \%$ (absolute change).

\subsection{Measuring sequence}

Figure 2 shows the RH inside the WFIMS, DMA classifying voltage, and WFIMS separator voltage, during an example sequence for the hygroscopic growth measurements of ambient aerosols. The sequence includes five RH levels ( $20 \%$, $40 \%, 60 \%, 75 \%$, and $85 \%$ ). At each RH level, hygroscopic growth is measured for aerosol classified at six dry sizes of $35,50,75,110,165$, and $265 \mathrm{~nm}$ as recommended by the EUSAAR (European Supersites for Atmospheric Aerosol Research) project (Duplissy et al., 2009). Figure 2a shows the distribution of detected particle number $\left(R_{i}\right)$ as a function of the normalized $x$ location $(\tilde{x}$, i.e., normalized distance traveled by the particles along the direction of electric field in the separator) in the viewing windows of WFIMS (Kulkarni and Wang, 2006a, b). Under the uniform electric field inside the WFIMS separator, larger particles travel a shorter distance in the direction of the electric field and are detected with lower $\tilde{x}$ values. In comparison, smaller particles travel further and are therefore detected at locations corresponding to higher $\tilde{x}$ values. At each of the five RH levels, the DMA voltage is stepped through six voltages $(288,562,1176,2296$, 4435 , and $8980 \mathrm{~V}$ ) to classify particles with diameter ranging from 35 to $265 \mathrm{~nm}$ (Fig. 2b). The WFIMS has a dynamic size range of a factor of 10 in electrical mobility (Kulkarni and Wang, 2006a), and its separator voltage is varied based on the DMA voltage to cover the size range of humidified particles (i.e., 350, 650, 1400, 3000, 4500, and $5500 \mathrm{~V}$ ). The upper limit of the WFIMS voltage is set at $5500 \mathrm{~V}$ to eliminate the possibility of arcing when operated at a high $\mathrm{RH}$ (i.e., $85 \%$ ). The change of WFIMS voltage slightly lags (approximately $3 \mathrm{~s}$ ) the DMA classifying voltage to offset the flow transport time between the outlet of the DMA and the exit of the WFIMS separator. The mean growth factor, i.e., the ratio of average humidified particle diameter measured by the WFIMS to the DMA-selected dry particle diameter, varies substantially among different particle sizes, indicating a strong size dependence of aerosol hygroscopic growth (Fig. 2c). 


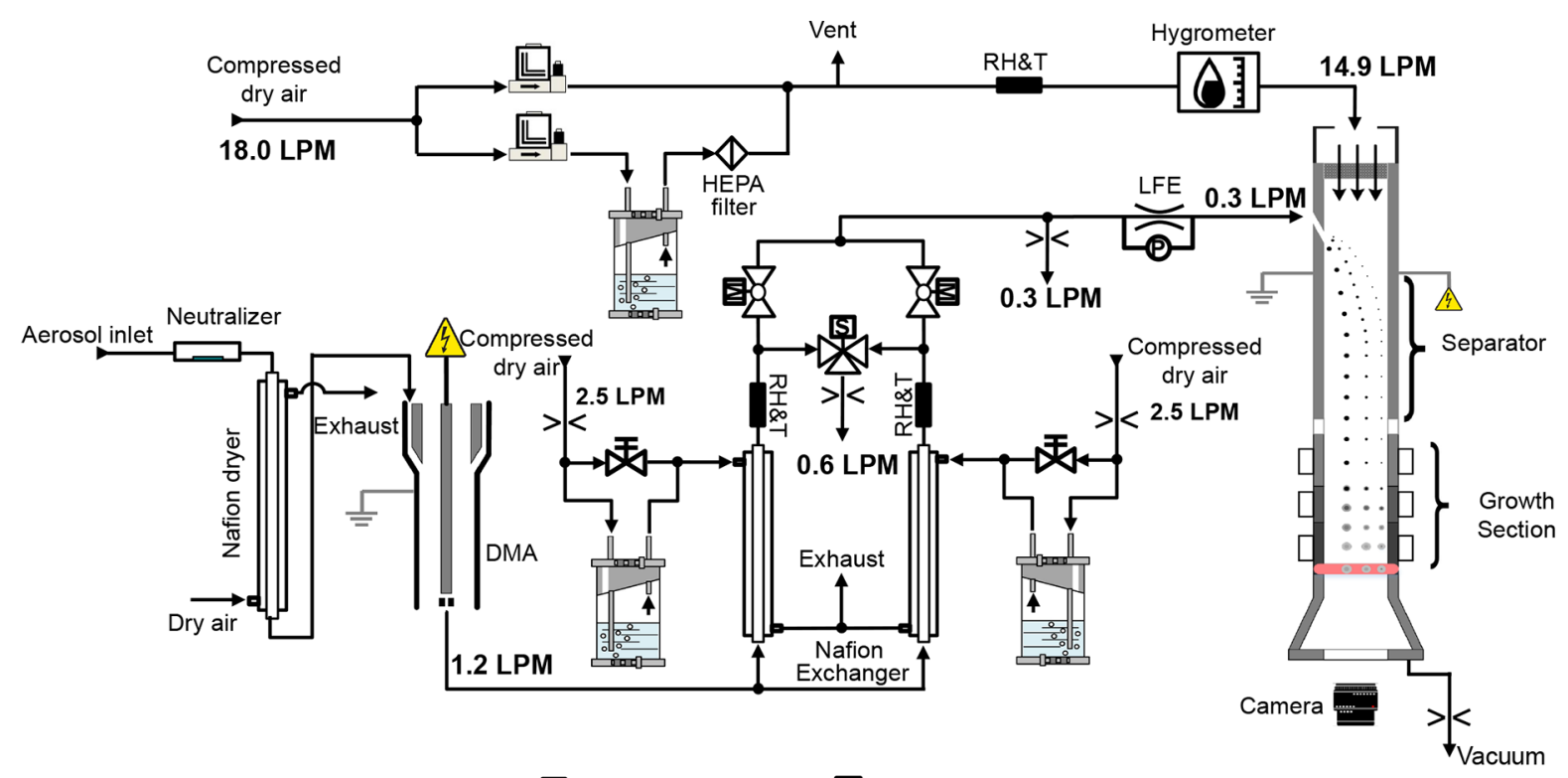

Mass flow controller $\bowtie$ Proportional valve

Figure 1. Schematic diagrams of dual-channel humidity-controlled fast integrated mobility spectrometer.
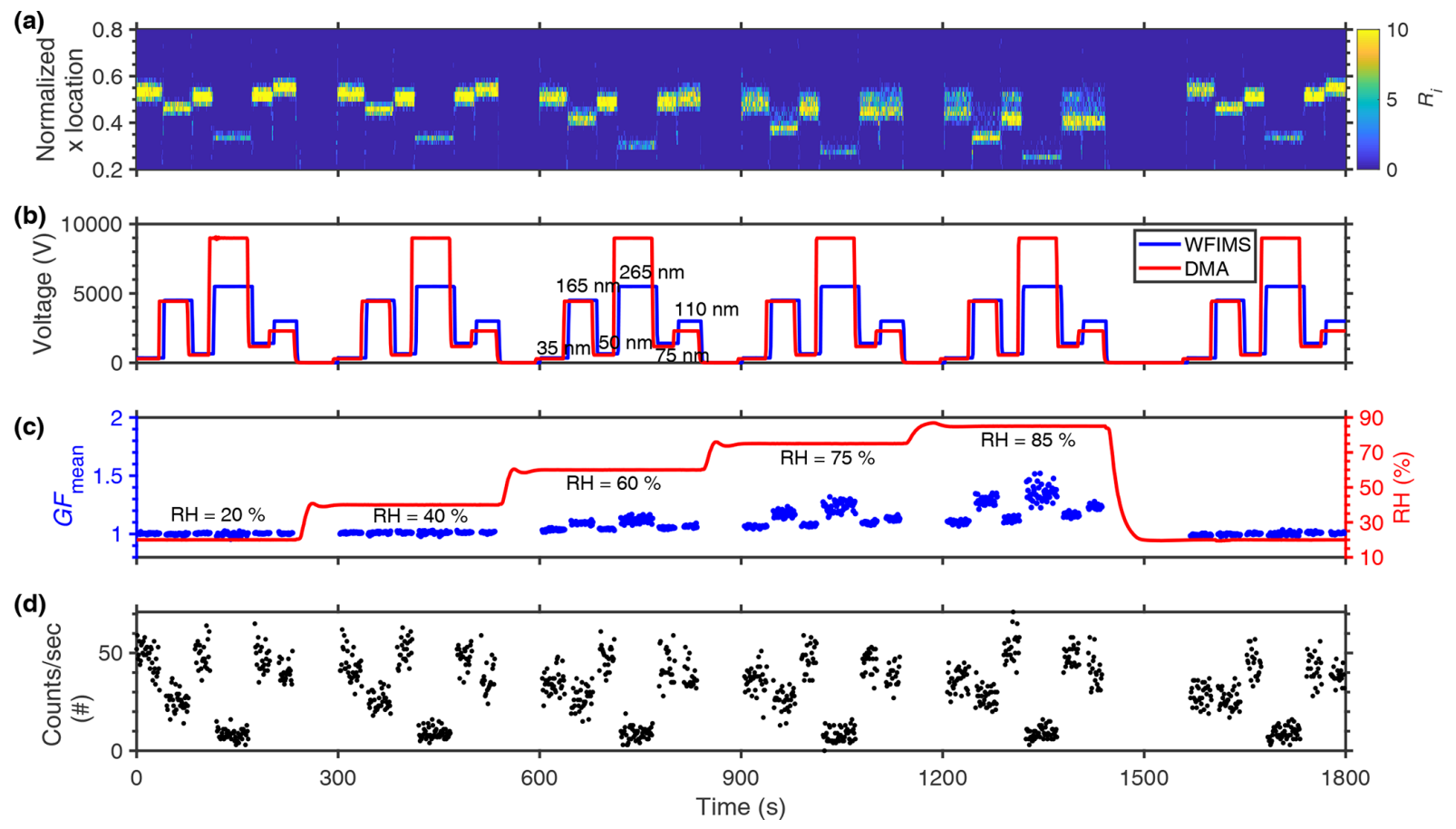

Figure 2. Example of the hygroscopic growth measurement sequence of ambient aerosols with six dry sizes $(35,50,75,110,165$, and $265 \mathrm{~nm})$ under five RHs $(20 \%, 40 \%, 60 \%, 75 \%$, and $85 \%)$. (a) The number of particles $\left(R_{i}\right)$ detected by WFIMS as a function of normalized $x$ locations within the viewing window and time. (b) The DMA classifying voltage (red line) and WFIMS separator voltage (blue line). (c) RH inside the WFIMS separator and mean growth factor measured by HFIMS as a function of time. (d) Actual particle count rate of HFIMS as a function of time. 
The particle residence time inside the DMA and the time required for particles to travel from the DMA outlet to the WFIMS separator leads to "dead time" following changes in classified particle size. Given the parabolic flow profile in the tubing, particles travel with a range of velocities inside the HFIMS. As a result, following a change in the DMA classifying voltage, it takes some time for the vast majority of the particles classified at the previous size to exit the system. During this transition time, measurements may be strongly affected by particles classified at the previous size, especially when the particle concentration at the new size is much lower. Such transition time is common in measurements of size-resolved aerosol hygroscopicity. For example, in DASH-SP, it requires a maximum transition time of $17 \mathrm{~s}$ to switch between different DMA-selected sizes (Sorooshian et al., 2008). For traditional HTDMA, a transition time on the order of $20 \mathrm{~s}$ is negligible when compared to the long measurement time (i.e., several minutes). However, such transition time rivals the measurement time of HFIMS at each particle size and is one of the main obstacles for fast measurements at multiple sizes. Here the transition time is minimized by optimizing the size sequence as $35 \rightarrow 165 \rightarrow 50 \rightarrow 265 \rightarrow 75 \rightarrow 110 \mathrm{~nm}$. At an RH of $85 \%$ or lower, the maximum range of growth factor (i.e., the ratio of humidified particle diameter to that of dry particles) for atmospheric aerosols is 0.8-2.0 (Gysel et al., 2007), within the minimum hygroscopic growth factor range (i.e., 0.8 to 2.4) of HFIMS. For example, for dry particles of $35 \mathrm{~nm}$, the diameter of humidified particles ranges from 28 to $84 \mathrm{~nm}$. For the next dry size of $165 \mathrm{~nm}$ in the sequence, the possible size range of humidified particles is between 132 and $396 \mathrm{~nm}$. Because there is no overlap in the two size ranges of humidified particles, measurements at $165 \mathrm{~nm}$ are not affected by $35 \mathrm{~nm}$ particles remaining in the HFIMS; therefore, the transition time between these two sizes ( 35 and $165 \mathrm{~nm}$ ) can be significantly reduced to $5 \mathrm{~s}$. In the optimized size sequence, an extended transition time of about $23 \mathrm{~s}$ is only required for the change of the classified size from 75 to $110 \mathrm{~nm}$ (i.e., the last step of the sequence). This relatively long transition time is necessary to ensure most of $75 \mathrm{~nm}$ particles have exited the HFIMS before the measurement at $110 \mathrm{~nm}$ commences. To balance the counting statistics at all six sizes, we determined the sample times based on typical continental aerosol size distributions, and they are 35, 25, 25, 20, 35, and $50 \mathrm{~s}$ for $35,50,75,110,165,265 \mathrm{~nm}$, respectively. The sample times may be adjusted dynamically based on ambient aerosol size distributions. Figure $2 \mathrm{~d}$ shows the particle counts detected by WFIMS per second. Because WFIMS measures aerosol size distribution at a time resolution of $1 \mathrm{~s}$, sufficient particle counts (e.g., over 300 in $50 \mathrm{~s}$ for $265 \mathrm{~nm}$ ) can be collected within the sample times for calculating the growth factor distribution (Wang et al., 2019). With this optimized size sequence, measurements of the hygroscopic growth at a single RH for six particle sizes can be made every $5 \mathrm{~min}$. In $25 \mathrm{~min}$, which HTDMA typically requires to complete measurements of six particle sizes at a single RH, HFIMS can provide particle hygroscopic growth at five RH levels from $20 \%$ to $85 \%$ for all six particle sizes.

\section{Results and discussion}

\subsection{Hygroscopic growth factor of ammonium sulfate particles}

The capability of the HFIMS to accurately characterize particle hygroscopic growth was evaluated by measuring laboratory-generated ammonium sulfate particles, whose hygroscopic growth behavior has been well documented (Onasch et al., 1999; Martin, 2000). First, the sizing accuracy of WFIMS is confirmed by the excellent agreement between the mean diameter measured by WFIMS under dry conditions (i.e., $\mathrm{RH}=20 \%$ ) and DMA centroid diameter (Fig. 3). For six nominal sizes, i.e., 35, 50, 75, 110, 165, and $265 \mathrm{~nm}$, the maximum difference between WFIMS measured mean diameter and DMA centroid diameter is below $2 \%$.

We further examine the accuracy of HFIMS measurements by comparing hygroscopic growth of ammonium sulfate particles measured by the HFIMS with theoretical values. Figure 4 shows the size-resolved hygroscopic growth factor (GF) as a function of $\mathrm{RH}$ for ammonium sulfate particles with diameters of $35,50,75,110,165$, and $265 \mathrm{~nm}$, respectively. The solid orange and purple lines represent theoretical predictions of the growth factor curve with and without Kelvin effect taken into consideration, respectively (Biskos et al., 2006; Bezantakos et al., 2016). The growth factor curve predicted by Extended Aerosol Inorganic Model (E-AIM) (Clegg et al., 1998; Wexler and Clegg, 2002) is shown by the green lines, and it agrees well with those predicted by the model with Kelvin effect neglected. The HFIMS-measured hygroscopic growth curves show that deliquescence started at $\sim 79.8 \% \mathrm{RH}$, in agreement with previous studies (Tang and Munkelwitz, 1993; Martin, 2000). There is an increase of $1 \% \mathrm{RH}$ of deliquescence $\mathrm{RH}$ observed for smaller particles (i.e., 35 and $50 \mathrm{~nm}$ ), and it is likely due to increased equilibrium water vapor pressure over the surface of smaller droplets (i.e., Kelvin effect) (Hämeri et al., 2000). Above the deliquescence point (i.e., $\mathrm{RH}>80 \%$ ), the hygroscopic growth measured by the HFIMS is in good agreement with those predicted by the model with Kelvin effect taken into account. Owing to Kelvin effect, particle hygroscopic growth decreases with decreasing dry particle size. For example, at $85 \% \mathrm{RH}$, the hygroscopic growth factor of $265 \mathrm{~nm}$ particles is around 1.57, and it decreases to around 1.50 for particles of $35 \mathrm{~nm}$. 

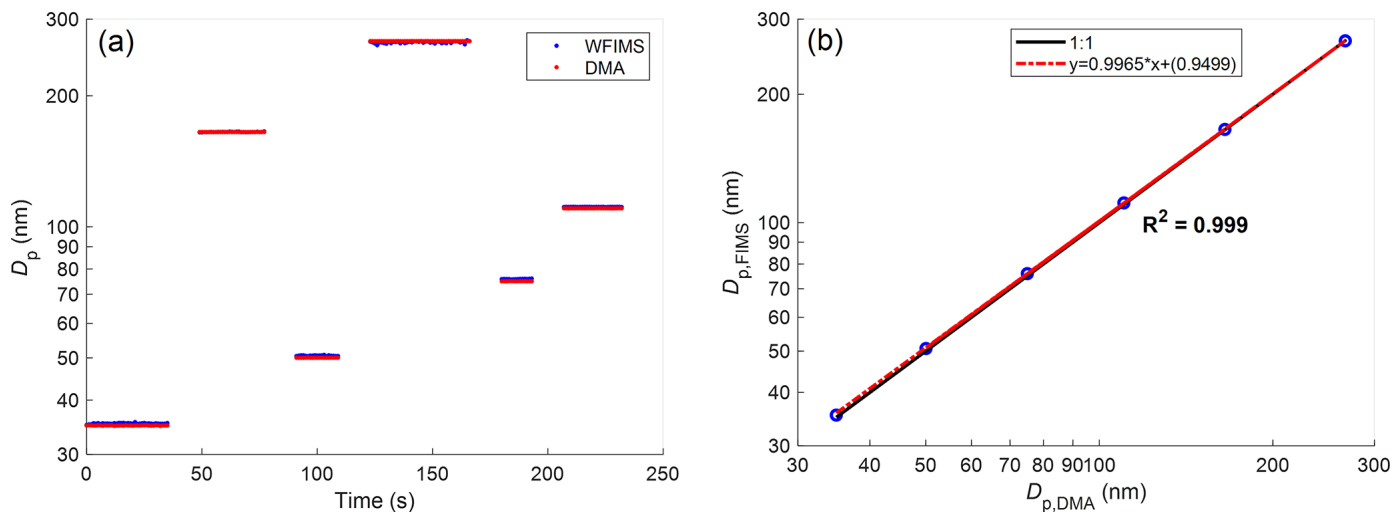

Figure 3. (a) Time series of mean diameters measured by WFIMS at an RH of $20 \%$ and DMA-selected sizes. (b) Scatterplot comparing DMA-selected particle size and WFIMS measured particle size and linear regression.
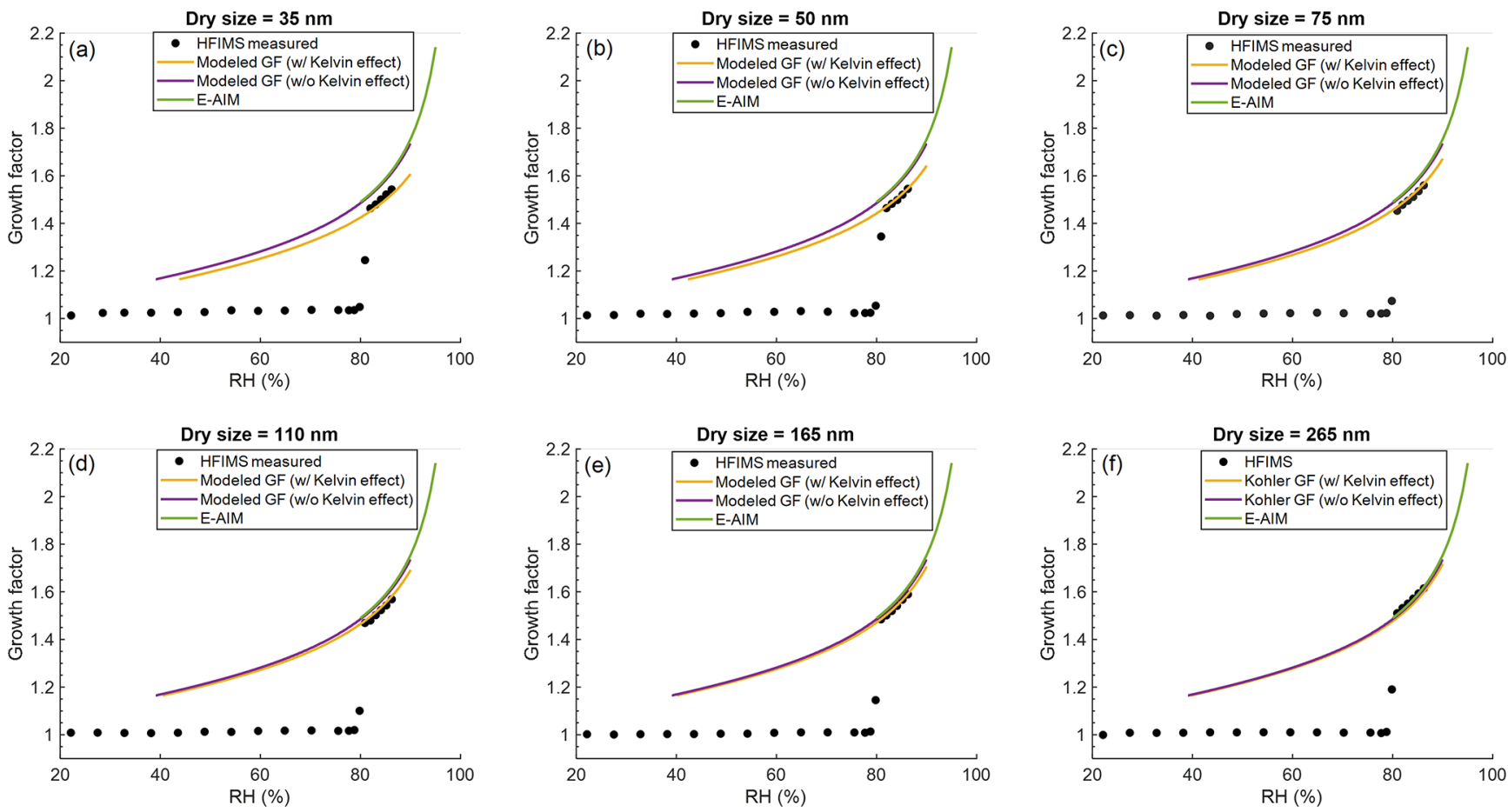

Figure 4. Hygroscopic growth curves of ammonium sulfate particles for six DMA-selected sizes (35, 50, 75, 110, 165, and 265 nm). Black circles present growth factor derived from HFIMS measurements. Solid lines are model predictions of the growth factor curves with and without Kevin effects and calculated from E-AIM model.

\subsection{Hygroscopic growth measurement of ambient aerosols}

\subsubsection{High time resolution measurements of hygroscopic properties of ambient aerosol}

Hygroscopic growth of ambient aerosols was measured by the HFIMS on the Danforth campus of Washington University in St. Louis, USA $\left(38^{\circ} 38^{\prime} \mathrm{N}, 90^{\circ} 18^{\prime} \mathrm{W}, 10 \mathrm{~m}\right.$ a.s.l. $)$, which is just beyond the western edge of the City of St. Louis. The measurement sequence is shown in Fig. 2.
Aerosol size distribution ranging from 11.7 to $429.4 \mathrm{~nm}$ in particle diameter was measured concurrently by a SMPS (model 3938, TSI Inc.). Prior to the SMPS measurement, the aerosol sample was dried to an RH below $30 \%$ using a diffusion dryer. Figure 5a shows the evolution of aerosol size distribution during a period of $3 \mathrm{~d}$ (1-4 March 2021). Each particle size distribution was fitted by a sum of up to three lognormal modes. The time series of the fitted diameter of the dominant mode (i.e., the mode with the highest number concentration) is shown by black dots in Fig. 5a. Strong variations in both aerosol size and number concentration were 


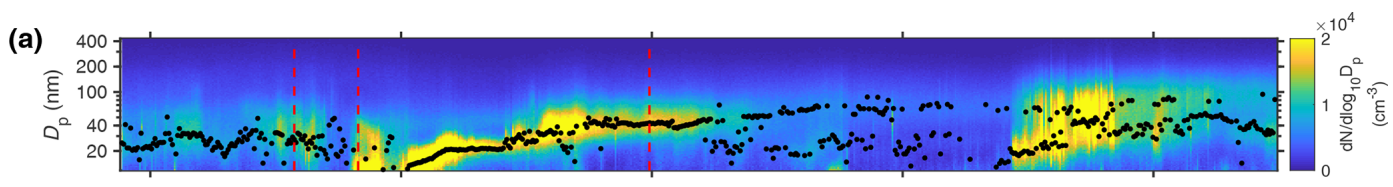

(b)

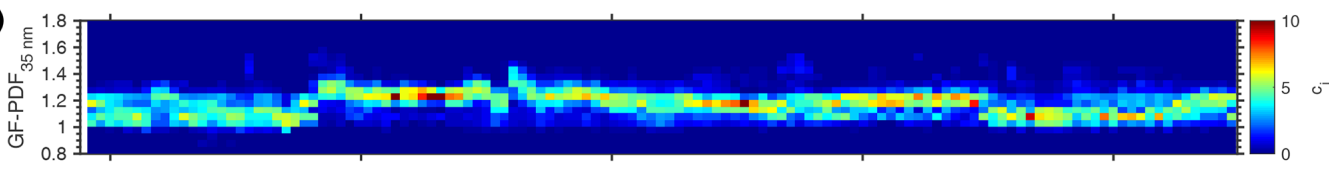

(c)

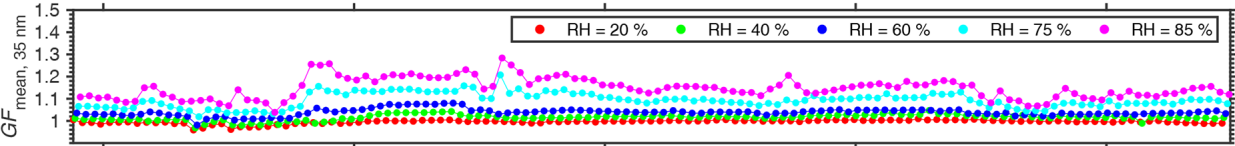

(d)

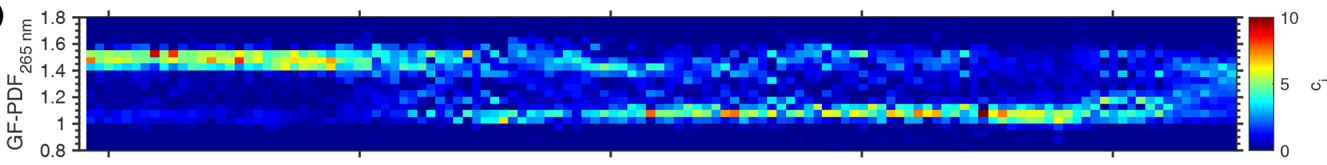

(e)

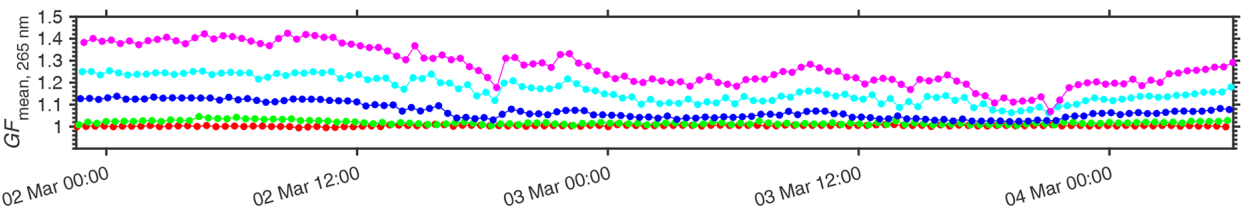

Figure 5. Aerosol size distribution measured by SMPS and GF-PDF retrieved from HFIMS measurements on the Danforth campus of Washington University in St. Louis from 1-4 March 2021. (a) Temporal evolution of aerosol size distributions ranging from 11.7 to 429.4 nm. Black dots are the fitted geometric mean diameter of the mode with the highest number concentration. (b, d) Temporal evolution of probability density function of growth factor of 35 and $265 \mathrm{~nm}$ particles at $85 \%$ RH. (c, e) Time series of mean growth factor of 35 and $265 \mathrm{~nm}$ particles at five RH levels $(20 \%, 40 \%, 60 \%, 75 \%$, and $85 \%)$.

evident during the sampling period. The high concentration of nucleation mode particles and the continuous increase of the mode diameter indicate a regional new particle formation (NPF) followed by condensational growth of newly formed particles on 2 March. The NPF event was observed at around 10:00 LT (local time) and the newly formed particles continued to grow until the early morning of the next day (3 March).

The probability density function of the hygroscopic growth factor (GF-PDF) is retrieved from the HFIMS measurements using an inversion routine described in Wang et al. (2019). We note that particles carrying multiple charges could contribute substantially to the aerosols classified by the DMA, especially for particles larger than $100 \mathrm{~nm}$ (Shen et al., 2021). This multiple-charge effect is not currently accounted for in the inversion routine and will be a subject of future study. The high time resolution and size-resolved GF-PDF captures the variations of the aerosol hygroscopic growth and the mixing state with time, shedding light on the evolution of aerosol particles. Figure $5 \mathrm{~b}$ and d show the temporal variations of the GF-PDF at $85 \%$ RH for 35 and $265 \mathrm{~nm}$ particles, which represent those grown from newly formed particles and the pre-existing particles, respectively (Wu et al., 2016). The time series of mean GF under the five RHs $(20 \%, 40 \%$,
$60 \%, 75 \%$, and $85 \%$ ) for 35 and $265 \mathrm{~nm}$ particles are shown in Fig. $5 \mathrm{c}$ and e. The mean GFs are essentially 1 at $20 \%$ and $40 \% \mathrm{RH}$ for both 35 and $265 \mathrm{~nm}$ particles, indicating negligible water uptake in the low RH range. However, particles at the two sizes exhibit different hygroscopic growth at elevated RHs and mixing states, especially during the NPF event. Particles with a diameter of $35 \mathrm{~nm}$ show a unimodal GF-PDF at $85 \%$ RH during most of the $3 \mathrm{~d}$ measurement period (Fig. 5b), suggesting an internal mixture. The mean GF of $35 \mathrm{~nm}$ particles at $85 \% \mathrm{RH}$ remained low (i.e., $\sim 1.1$ ) before the NPF event, and it jumped from $\sim 1.1$ to $\sim 1.25$ at the beginning of the event (i.e., $\sim 10: 00 \mathrm{am} \mathrm{LT}$ on $2 \mathrm{March}$ ). This GF increase is likely due to the participation of sulfuric acid in the formation and early growth of the new particles (Shantz et al., 2012; Wu et al., 2016). In comparison, the GFPDF of $265 \mathrm{~nm}$ particles was initially dominated by a single mode at $\sim 1.5$, but it gradually transitioned to a bimodal pattern as the NPF event proceeded, indicating a shift from internal mixtures to external mixtures. The bimodal GF-PDF consists of one mode with low GF (i.e., close to 1) and one with GF at $\sim 1.5$. The variation of GF-PDF suggests that the pre-existing aerosol changed from one that was dominated by aged particles with large contributions of inorganics (e.g., sulfate) to a mixture of both aged particles and freshly emit- 

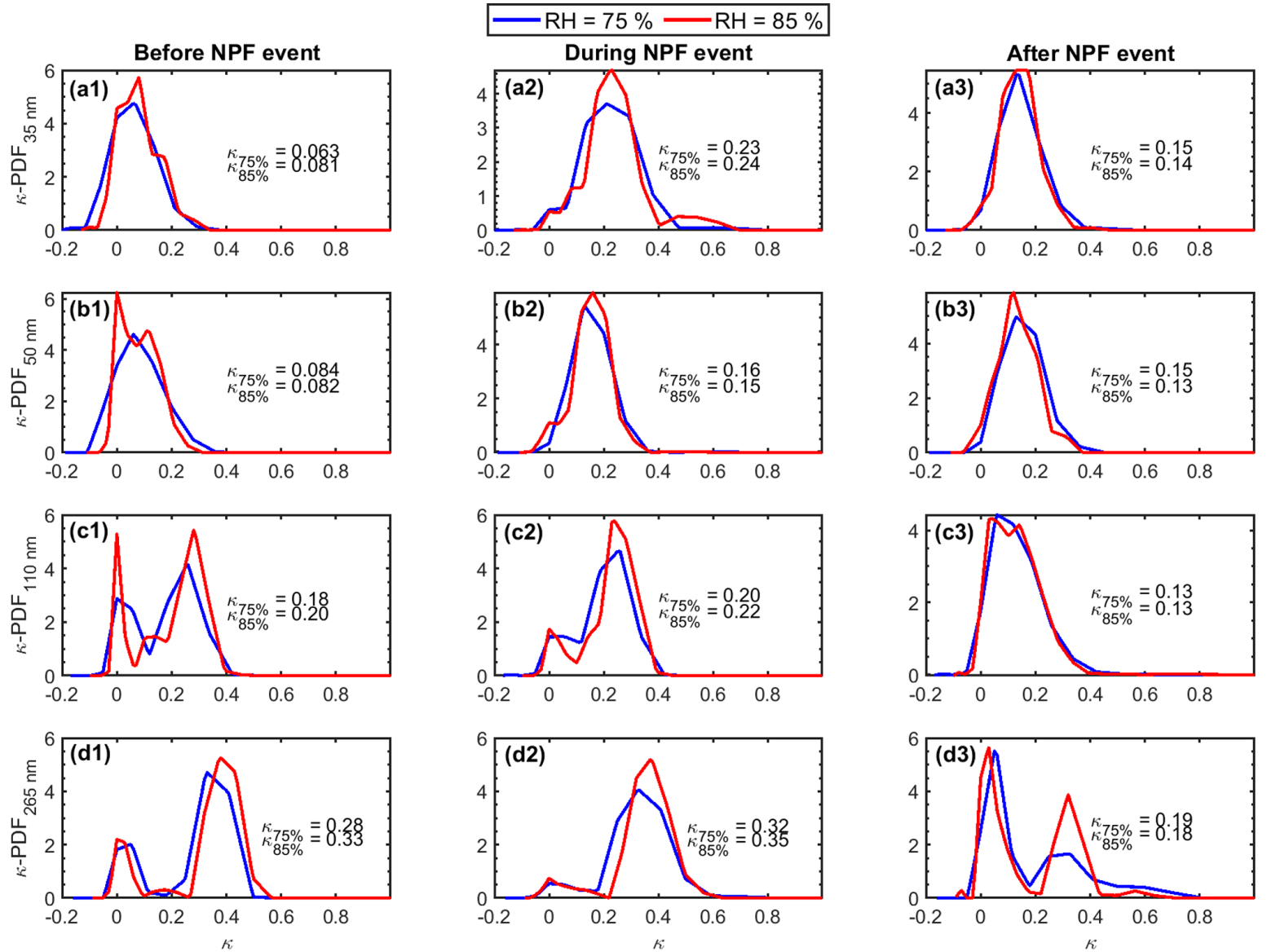

Figure 6. Probability density function of hygroscopicity parameter ( $\kappa$-PDF) before (a1-d1), during (a2-d2) and after (a3-d3) the NPF event period (06:53, 09:57, and 23:53 LT, respectively) on 2 March 2021. The mean $\kappa$ value derived from each $\kappa$-PDF is also given in the plots.

ted ones that consisted mostly of low hygroscopicity particles (e.g., organic and soot particles). As a result, the mean GF of $265 \mathrm{~nm}$ particles decreased from 1.4 at the start of NPF event to 1.2 at $\sim 18: 00 \mathrm{pm} \mathrm{LT}$ on 2 March. This transition is likely due to a change of the air mass sampled.

\subsubsection{RH and size dependence of hygroscopicity distribution}

At a given RH, particle hygroscopic growth depends on the hygroscopicity parameter (i.e., $\kappa$ ), which is a function of thermodynamic properties, including molar volume, activity coefficient, and surface activity, of the species within the particles (Petters and Kreidenweis, 2007). The probability density function of hygroscopicity, $\kappa$-PDF, is converted from GF-PDF based on the following relationship (Petters and Kreidenweis, 2007; Su et al., 2010; Liu et al., 2011):

$\kappa(\mathrm{GF})=\left(\mathrm{GF}^{3}-1\right) \cdot\left[\frac{1}{\mathrm{RH}} \exp \left(\frac{4 \sigma_{\mathrm{s} / \mathrm{a}} M_{\mathrm{w}}}{R T \rho_{\mathrm{w}} D_{\mathrm{p}} \mathrm{GF}}\right)-1\right]$,

where $D_{\mathrm{p}}$ is the diameter of dry particle and GF is the hygroscopic growth factor at different RHs measured by HFIMS. $\sigma_{\mathrm{s} / \mathrm{a}}$ is the surface tension of the solution-air interface, $M_{\mathrm{w}}$ is the molecular weight of water, $R$ is the universal gas constant, $T$ is the absolute temperature, and $\rho_{\mathrm{w}}$ is the density of water.

Figure 6 shows the $\kappa$-PDF derived from GF-PDF at $75 \%$ and $85 \%$ RH before, during, and after the NPF event, corresponding to 06:53, 09:57, and 23:53 LT on 2 March, as marked by dashed red lines in Fig. 5a. At all three time points, $\kappa$-PDF varies with particle diameter, indicating strong size dependence of particle chemical compositions. $\kappa$-PDF is unimodal for particles with diameters of 35 and $50 \mathrm{~nm}$, showing that these particles are internally mixed. The mean $\kappa$ values for 35 and $50 \mathrm{~nm}$ particles show substantial increases at the start of the NPF event compared to those prior to the event (e.g., mean $\kappa$ at $85 \%$ RH increased from 0.08 to 0.24 for $35 \mathrm{~nm}$ particles). This trend is consistent with the contribution of sulfuric acid to the formation and early growth of new particles (Kulmala et al., 2004; Wu et al., 2016). The mean $\kappa$ values for 35 and $50 \mathrm{~nm}$ particles then exhibit a slight decrease following the NPF event, possibly due to the depletion of sulfuric acid and increased contribution of secondary organics to the growth of nucleation mode particles in the 
late stage of the NPF event (Dusek et al., 2010; Zheng et al., 2020). Prior to and at the beginning of the NPF event, the $\kappa$ PDF for particles of $265 \mathrm{~nm}$ was dominated by a mode with $\kappa$ value at $\sim 0.4$, consistent with the picture that pre-existing particles were dominated by aged particles with large contributions of inorganics (e.g., sulfate). The $\kappa$-PDF becomes bimodal following the NPF events, suggesting a transition of the pre-existing particles to an external mixture of freshly emitted particles with low hygroscopicity and aged background particles with higher hygroscopicity. The $\kappa$-PDFs derived from GF-PDF under two RHs (75\% and $85 \%)$ mostly agreed well with each other, except for $265 \mathrm{~nm}$ particles prior to and at the start of the NPF, for which the dominant, more hygroscopic mode shows a slightly higher $\kappa$ value at $85 \%$ (Fig. $6 \mathrm{~d} 1-\mathrm{d} 2$ ). This higher $\kappa$ at $85 \%$ RH may be due to an increase of the amount of water in the humidified particles that is available for the solvation of organics with low water solubility (Petters et al., 2009).

\section{Summary}

In this study, we present a humidity-controlled fast integrated mobility spectrometer (HFIMS) for fast measurements of aerosol hygroscopic growth. The HFIMS can measure the distributions of particle hygroscopic growth factor at six diameters $(35,50,75,110,165$, and $265 \mathrm{~nm})$ under five RH levels ( $20 \%, 40 \%, 60 \%, 75 \%$, and $85 \%$, respectively) within $25 \mathrm{~min}$. All 30 measurements are completed in less than 1 min per measurement, on average. The fast measurement speed is achieved by combining the rapid measurements of aerosol size distribution by a water-based FIMS, the capability of a dual-channel humidifier for quickly stepping among different RH levels, and an optimized measurement sequence that minimizes the transition time between measurements at different particle sizes. Measurements of laboratory-generated ammonium sulfate aerosol standards show that the HFIMS is capable of accurately measuring aerosol hygroscopic growth. The capability of the HFIMS is also demonstrated by measuring ambient aerosols over a period of $\sim 3 \mathrm{~d}$. The HFIMS measurements successfully capture the temporal variations and the size and $\mathrm{RH}$ dependences of aerosol hygroscopic growth, which provide insights into the evolution of atmospheric aerosol processes.

Data availability. Datasets related to this paper will be provided by the corresponding author (Jian Wang, jian@wustl.edu) upon request.

Author contributions. JW, StS, JZ, and YW designed the instrument. JW and JZ designed the study. JZ carried out the experiments. JZ and JW prepared the manuscript with contributions from all coauthors.
Competing interests. The authors declare that they have no conflict of interest.

Disclaimer. Publisher's note: Copernicus Publications remains neutral with regard to jurisdictional claims in published maps and institutional affiliations.

Acknowledgements. We acknowledge the funding support from U.S. Department of Energy's Small Business Innovation Research (SBIR) program under contract DE-SC0013103 and Small Business Technology Transfer (STTR) program under contract DESC0006312.

Financial support. This research has been supported by the U.S. Department of Energy, Small Business Innovative Research and Small Business Technology Transfer (grant nos. DE-SC0013103 and DE-SC0006312).

Review statement. This paper was edited by Mingjin Tang and reviewed by two anonymous referees.

\section{References}

Bezantakos, S., Huang, L., Barmpounis, K., Martin, S., and Biskos, G.: Relative humidity non-uniformities in Hygroscopic Tandem Differential Mobility Analyzer measurements, J. Aerosol Sci., 101, 1-9, https://doi.org/10.1016/j.jaerosci.2016.07.004, 2016.

Biskos, G., Paulsen, D., Russell, L. M., Buseck, P. R., and Martin, S. T.: Prompt deliquescence and efflorescence of aerosol nanoparticles, Atmos. Chem. Phys., 6, 4633-4642, https://doi.org/10.5194/acp-6-4633-2006, 2006.

Cerully, K. M., Raatikainen, T., Lance, S., Tkacik, D., Tiitta, P., Petäjä, T., Ehn, M., Kulmala, M., Worsnop, D. R., Laaksonen, A., Smith, J. N., and Nenes, A.: Aerosol hygroscopicity and CCN activation kinetics in a boreal forest environment during the 2007 EUCAARI campaign, Atmos. Chem. Phys., 11, 12369-12386, https://doi.org/10.5194/acp-11-12369-2011, 2011.

Clegg, S. L., Brimblecombe, P., and Wexler, A. S.: Thermodynamic Model of the System $\mathrm{H}^{+}-\mathrm{NH}_{4}{ }^{+}-\mathrm{SO}_{4}{ }^{2-}-\mathrm{NO}_{3}{ }^{-}-\mathrm{H}_{2} \mathrm{O}$ at Tropospheric Temperatures, J. Phys. Chem. A, 102, 2137-2154, https://doi.org/10.1021/jp973042r, 1998.

Duplissy, J., Gysel, M., Sjogren, S., Meyer, N., Good, N., Kammermann, L., Michaud, V., Weigel, R., Martins dos Santos, S., Gruening, C., Villani, P., Laj, P., Sellegri, K., Metzger, A., McFiggans, G. B., Wehrle, G., Richter, R., Dommen, J., Ristovski, Z., Baltensperger, U., and Weingartner, E.: Intercomparison study of six HTDMAs: results and recommendations, Atmos. Meas. Tech., 2, 363-378, https://doi.org/10.5194/amt-2363-2009, 2009.

Dusek, U., Frank, G. P., Curtius, J., Drewnick, F., Schneider, J., Kürten, A., Rose, D., Andreae, M. O., Borrmann, S., and Pöschl, U.: Enhanced organic mass fraction and decreased hygroscopicity of cloud condensation nuclei $(\mathrm{CCN})$ during new 
particle formation events, Geophys. Res. Lett., 37, L03804, https://doi.org/10.1029/2009GL040930, 2010.

George, I. J. and Abbatt, J. P. D.: Heterogeneous oxidation of atmospheric aerosol particles by gas-phase radicals, Nat. Chem., 2, 713-722, https://doi.org/10.1038/nchem.806, 2010.

Gysel, M., Crosier, J., Topping, D. O., Whitehead, J. D., Bower, K. N., Cubison, M. J., Williams, P. I., Flynn, M. J., McFiggans, G. B., and Coe, H.: Closure study between chemical composition and hygroscopic growth of aerosol particles during TORCH2, Atmos. Chem. Phys., 7, 6131-6144, https://doi.org/10.5194/acp7-6131-2007, 2007.

Hämeri, K., Väkevä, M., Hansson, H.-C., and Laaksonen, A.: Hygroscopic growth of ultrafine ammonium sulphate aerosol measured using an ultrafine tandem differential mobility analyzer, J. Geophys. Res.-Atmos., 105, 22231-22242, https://doi.org/10.1029/2000JD900220, 2000.

Hering, S. V., Spielman, S. R., and Lewis, G. S.: Moderated, Water-Based, Condensational Particle Growth in a Laminar Flow, Aerosol Sci. Tech., 48, 401-408, https://doi.org/10.1080/02786826.2014.881460, 2014.

Hersey, S., Sorooshian, A., Murphy, S., Flagan, R., and Seinfeld, J.: Aerosol hygroscopicity in the marine atmosphere: a closure study using high-time-resolution, multiple-RH DASH-SP and size-resolved C-ToF-AMS data, Atmos. Chem. Phys., 9, 25432554, 2009.

Kulkarni, P. and Wang, J.: New fast integrated mobility spectrometer for real-time measurement of aerosol size distribution - I: Concept and theory, J. Aerosol Sci., 37, 1303-1325, https://doi.org/10.1016/j.jaerosci.2006.01.005, 2006a.

Kulkarni, P. and Wang, J.: New fast integrated mobility spectrometer for real-time measurement of aerosol size distribution: II. Design, calibration, and performance characterization, J. Aerosol Sci., 37, 1326-1339, https://doi.org/10.1016/j.jaerosci.2006.01.010, 2006b.

Kulmala, M., Laakso, L., Lehtinen, K. E. J., Riipinen, I., Dal Maso, M., Anttila, T., Kerminen, V.-M., Hõrrak, U., Vana, M., and Tammet, H.: Initial steps of aerosol growth, Atmos. Chem. Phys., 4, 2553-2560, https://doi.org/10.5194/acp-4-2553-2004, 2004.

Leinert, S. and Wiedensohler, A.: A DMA and APS based technique for measuring aerodynamic hygroscopic growth factors of micrometer-size aerosol particles, J. Aerosol Sci., 39, 393-402, https://doi.org/10.1016/j.jaerosci.2007.12.009, 2008.

Liu, P., Song, M., Zhao, T., Gunthe, S. S., Ham, S., He, Y., Qin, Y. M., Gong, Z., Amorim, J. C., Bertram, A. K., and Martin, S. T.: Resolving the mechanisms of hygroscopic growth and cloud condensation nuclei activity for organic particulate matter, Nat. Commun., 9, 4076, https://doi.org/10.1038/s41467-018-066222, 2018.

Liu, P. F., Zhao, C. S., Göbel, T., Hallbauer, E., Nowak, A., Ran, L., Xu, W. Y., Deng, Z. Z., Ma, N., Mildenberger, K., Henning, S., Stratmann, F., and Wiedensohler, A.: Hygroscopic properties of aerosol particles at high relative humidity and their diurnal variations in the North China Plain, Atmos. Chem. Phys., 11, 3479-3494, https://doi.org/10.5194/acp-11-3479-2011, 2011.

Lopez-Yglesias, X. F., Yeung, M. C., Dey, S. E., Brechtel, F. J., and Chan, C. K.: Performance Evaluation of the Brechtel Mfg. Humidified Tandem Differential Mobility Analyzer (BMI HTDMA) for Studying Hygroscopic Proper- ties of Aerosol Particles, Aerosol Sci. Tech., 48, 969-980, https://doi.org/10.1080/02786826.2014.952366, 2014.

Martin, S. T.: Phase Transitions of Aqueous Atmospheric Particles, Chem. Rev., 100, 3403-3454, https://doi.org/10.1021/cr990034t, 2000.

Massling, A., Niedermeier, N., Hennig, T., Fors, E. O., Swietlicki, E., Ehn, M., Hämeri, K., Villani, P., Laj, P., Good, N., McFiggans, G., and Wiedensohler, A.: Results and recommendations from an intercomparison of six Hygroscopicity-TDMA systems, Atmos. Meas. Tech., 4, 485-497, https://doi.org/10.5194/amt-4485-2011, 2011.

Onasch, T. B., Siefert, R. L., Brooks, S. D., Prenni, A. J., Murray, B., Wilson, M. A., and Tolbert, M. A.: Infrared spectroscopic study of the deliquescence and efflorescence of ammonium sulfate aerosol as a function of temperature, J. Geophys. Res.-Atmos., 104, 21317-21326, https://doi.org/10.1029/1999JD900384, 1999.

Pajunoja, A., Lambe, A. T., Hakala, J., Rastak, N., Cummings, M. J., Brogan, J. F., Hao, L., Paramonov, M., Hong, J., Prisle, N. L., Malila, J., Romakkaniemi, S., Lehtinen, K. E. J., Laaksonen, A., Kulmala, M., Massoli, P., Onasch, T. B., Donahue, N. M., Riipinen, I., Davidovits, P., Worsnop, D. R., Petäjä, T., and Virtanen, A.: Adsorptive uptake of water by semisolid secondary organic aerosols, Geophys. Res. Lett., 42, 3063-3068, https://doi.org/10.1002/2015GL063142, 2015.

Peng, C., Wang, Y., Wu, Z., Chen, L., Huang, R.-J., Wang, W., Wang, Z., Hu, W., Zhang, G., Ge, M., Hu, M., Wang, X., and Tang, M.: Tropospheric aerosol hygroscopicity in China, Atmos. Chem. Phys., 20, 13877-13903, https://doi.org/10.5194/acp-2013877-2020, 2020.

Petters, M. D. and Kreidenweis, S. M.: A single parameter representation of hygroscopic growth and cloud condensation nucleus activity, Atmos. Chem. Phys., 7, 1961-1971, https://doi.org/10.5194/acp-7-1961-2007, 2007.

Petters, M. D., Wex, H., Carrico, C. M., Hallbauer, E., Massling, A., McMeeking, G. R., Poulain, L., Wu, Z., Kreidenweis, S. M., and Stratmann, F.: Towards closing the gap between hygroscopic growth and activation for secondary organic aerosol - Part 2: Theoretical approaches, Atmos. Chem. Phys., 9, 3999-4009, https://doi.org/10.5194/acp-9-3999-2009, 2009.

Pilinis, C., Pandis, S. N., and Seinfeld, J. H.: Sensitivity of direct climate forcing by atmospheric aerosols to aerosol size and composition, J. Geophys. Res.-Atmos., 100, 18739-18754, https://doi.org/10.1029/95JD02119, 1995.

Pinterich, T., Spielman, S. R., Hering, S., and Wang, J.: A waterbased fast integrated mobility spectrometer (WFIMS) with enhanced dynamic size range, Aerosol Sci. Tech., 51, 1212-1222, https://doi.org/10.1080/02786826.2017.1338664, 2017a.

Pinterich, T., Spielman, S. R., Wang, Y., Hering, S. V., and Wang, J.: A humidity-controlled fast integrated mobility spectrometer (HFIMS) for rapid measurements of particle hygroscopic growth, Atmos. Meas. Tech., 10, 4915-4925, https://doi.org/10.5194/amt-10-4915-2017, $2017 \mathrm{~b}$.

Rader, D. and McMurry, P. H.: Application of the tandem differential mobility analyzer to studies of droplet growth or evaporation, J. Aerosol Sci., 17, 771-787, 1986.

Rastak, N., Pajunoja, A., Acosta Navarro, J. C., Ma, J., Song, M., Partridge, D. G., Kirkevåg, A., Leong, Y., Hu, W. W., Taylor, N. F., Lambe, A., Cerully, K., Bougiatioti, A., Liu, P., Kre- 
jci, R., Petäjä, T., Percival, C., Davidovits, P., Worsnop, D. R., Ekman, A. M. L., Nenes, A., Martin, S., Jimenez, J. L., Collins, D. R., Topping, D. O., Bertram, A. K., Zuend, A., Virtanen, A., and Riipinen, I.: Microphysical explanation of the RH-dependent water affinity of biogenic organic aerosol and its importance for climate, Geophys. Res. Lett., 44, 5167-5177, https://doi.org/10.1002/2017GL073056, 2017.

Santarpia, J. L., Gasparini, R., Li, R., and Collins, D. R.: Diurnal variations in the hygroscopic growth cycles of ambient aerosol populations, J. Geophys. Res.-Atmos., 110, D03206, https://doi.org/10.1029/2004JD005279, 2005.

Shantz, N. C., Pierce, J. R., Chang, R. Y. W., Vlasenko, A., Riipinen, I., Sjostedt, S., Slowik, J. G., Wiebe, A., Liggio, J., Abbatt, J. P. D., and Leaitch, W. R.: Cloud condensation nuclei droplet growth kinetics of ultrafine particles during anthropogenic nucleation events, Atmos. Environ., 47, 389-398, https://doi.org/10.1016/j.atmosenv.2011.10.049, 2012.

Shen, C., Zhao, G., and Zhao, C.: Effects of multi-charge on aerosol hygroscopicity measurement by a HTDMA, Atmos. Meas. Tech., 14, 1293-1301, https://doi.org/10.5194/amt-141293-2021, 2021.

Sorooshian, A., Hersey, S., Brechtel, F. J., Corless, A., Flagan, R. C., and Seinfeld, J. H.: Rapid, size-resolved aerosol hygroscopic growth measurements: Differential aerosol sizing and hygroscopicity spectrometer probe (DASH-SP), Aerosol Sci. Tech., 42, 445-464, 2008.

Stolzenburg, M., Kreisberg, N., and Hering, S.: Atmospheric Size Distributions Measured by Differential Mobility Optical Particle Size Spectrometry, Aerosol Sci. Tech., 29, 402-418, https://doi.org/10.1080/02786829808965579, 1998.

Su, H., Rose, D., Cheng, Y. F., Gunthe, S. S., Massling, A., Stock, M., Wiedensohler, A., Andreae, M. O., and Pöschl, U.: Hygroscopicity distribution concept for measurement data analysis and modeling of aerosol particle mixing state with regard to hygroscopic growth and CCN activation, Atmos. Chem. Phys., 10, 7489-7503, https://doi.org/10.5194/acp-10-7489-2010, 2010.

Surratt, J. D., Chan, A. W. H., Eddingsaas, N. C., Chan, M., Loza, C. L., Kwan, A. J., Hersey, S. P., Flagan, R. C., Wennberg, P. O., and Seinfeld, J. H.: Reactive intermediates revealed in secondary organic aerosol formation from isoprene, P. Natl. Acad. Sci. USA, 107, 6640-6645, https://doi.org/10.1073/pnas.0911114107, 2010.

Swietlicki, E., Hansson, H.-C., Hämeri, K., Svenningsson, B., Massling, A., McFiggans, G., McMurry, P. H., Petäjä, T., Tunved, P., and Gysel, M.: Hygroscopic properties of submicrometer atmospheric aerosol particles measured with H-TDMA instruments in various environments - a review, Tellus B, 60, 432-469, 2008 .
Tang, I. and Munkelwitz, H.: Aerosol phase transformation and growth in the atmosphere, J. Appl. Meteorol., 33, 791-796, 1994.

Tang, I. N. and Munkelwitz, H. R.: Composition and temperature dependence of the deliquescence properties of hygroscopic aerosols, Atmos. Environ. A-Gen., 27, 467-473, https://doi.org/10.1016/0960-1686(93)90204-C, 1993.

Tang, M., Chan, C. K., Li, Y. J., Su, H., Ma, Q., Wu, Z., Zhang, G., Wang, Z., Ge, M., Hu, M., He, H., and Wang, X.: A review of experimental techniques for aerosol hygroscopicity studies, Atmos. Chem. Phys., 19, 12631-12686, https://doi.org/10.5194/acp-1912631-2019, 2019.

Wang, J., Flagan, R. C., Seinfeld, J. H., Jonsson, H. H., Collins, D. R., Russell, P. B., Schmid, B., Redemann, J., Livingston, J. M., Gao, S., Hegg, D. A., Welton, E. J., and Bates, D.: Clearcolumn radiative closure during ACE-Asia: Comparison of multiwavelength extinction derived from particle size and composition with results from Sun photometry, J. Geophys. Res.-Atmos., 107, 4688, https://doi.org/10.1029/2002JD002465, 2002.

Wang, Y., Zheng, G., Spielman, S. R., Pinterich, T., Hering, S. V., and Wang, J.: Retrieval of high time resolution growth factor probability density function from a humidity-controlled fast integrated mobility spectrometer, Aerosol Sci. Tech., 53, 1092-1106, 2019.

Wex, H., Petters, M. D., Carrico, C. M., Hallbauer, E., Massling, A., McMeeking, G. R., Poulain, L., Wu, Z., Kreidenweis, S. M., and Stratmann, F.: Towards closing the gap between hygroscopic growth and activation for secondary organic aerosol: Part $1-$ Evidence from measurements, Atmos. Chem. Phys., 9, 3987-3997, https://doi.org/10.5194/acp-9-3987-2009, 2009.

Wexler, A. S. and Clegg, S. L.: Atmospheric aerosol models for systems including the ions $\mathrm{H}^{+}, \mathrm{NH}_{4}{ }^{+}, \mathrm{Na}^{+}, \mathrm{SO}_{4}{ }^{2-}, \mathrm{NO}_{3}{ }^{-}$, $\mathrm{Cl}^{-}, \mathrm{Br}^{-}$, and $\mathrm{H}_{2} \mathrm{O}$, J. Geophys. Res.-Atmos., 107, $\mathrm{ACH} 14$ 11-ACH 14-14, https://doi.org/10.1029/2001JD000451, 2002.

Wu, Z. J., Zheng, J., Shang, D. J., Du, Z. F., Wu, Y. S., Zeng, L. M., Wiedensohler, A., and Hu, M.: Particle hygroscopicity and its link to chemical composition in the urban atmosphere of Beijing, China, during summertime, Atmos. Chem. Phys., 16, 1123 1138, https://doi.org/10.5194/acp-16-1123-2016, 2016.

Zheng, G., Kuang, C., Uin, J., Watson, T., and Wang, J.: Large contribution of organics to condensational growth and formation of cloud condensation nuclei $(\mathrm{CCN})$ in the remote marine boundary layer, Atmos. Chem. Phys., 20, 12515-12525, 2020. 